\title{
Determinants Of Integrated Performance Measurement Systems Usage: An Empirical Study
}

Mojca Marc, PhD, University of Ljubljana, Slovenia Darja Peljhan, University of Ljubljana, Slovenia Nina Ponikvar, University of Ljubljana, Slovenia Aleksandra Sobota, University of Ljubljana, Slovenia Metka Tekavcic, University of Ljubljana, Slovenia

\begin{abstract}
Performance management literature has been advocating the balanced use of non-financial measures alongside traditional financial measures, possibly within integrated performance measurement systems, since the early 1990's. The purpose of this paper is to explore how contextual factors (such as company size, industry, and market position), business objectives and knowledge about contemporary management tools influence the decision to implement Balanced Scorecard or similar integrated performance management systems. We tested our research propositions regarding the influence of these factors by using survey data and a logistic regression model. The study is based on a survey conducted in 2008 on a sample of 323 Slovenian companies. The sample consists of large, medium, and small firms from different industrial sectors, including manufacturing and service. Overall, our results confirm contextual factors, such as company size and industry, and knowledge about management tools as most important determinants of integrated performance measurement systems usage. Although market position and business objectives also receive some support for their influence, the results are generally weaker and more ambiguous.
\end{abstract}

Keywords: Performance measurement, Performance management, Balanced Scorecard, Contextual Factors, Knowledge, Business Objectives

\section{INTRODUCTION}

$\mathcal{P}$ erformance management literature has been advocating the balanced use of non-financial measures alongside traditional financial measures, possibly within integrated performance measurement systems, since the early 1990's. Among various proposed integrated performance measurement systems, Balanced Scorecard - proposed first by Kaplan and Norton in 1992- has received most attention among practitioners and academics. The diffusion of this and similar approaches for measuring performance has been notable during the last twenty years, but the proportion of companies using them is still below the expectations. The purpose of this paper is to explore how contextual factors (such as company size, industry, and market position), business objectives and knowledge about contemporary management tools influence the decision to implement Balanced Scorecard or similar integrated performance management systems.

Determinants of integrated performance measurement systems (IPMS) usage have been studied by only a few empirical studies, which mostly focused on manufacturing companies. By extending the domain of research also to service companies, our study adds to the body of knowledge in this area. The study is based on a survey conducted in 2008 on a sample of 323 Slovenian companies. The sample consists of large, medium, and small firms from different industrial sectors, including manufacturing and service. We use logistic regression to test the impact of contextual and other factors on the usage of integrated performance measurement systems. In the following paragraphs we first present our research hypotheses and their theoretical underpinnings. Next, we describe the 
methodological approach, follow with a section explaining the results, and finally wrap up with a discussion of results and their implications.

\section{RESEARCH PROPOSITIONS}

Many theoretical and empirical contributions have confirmed that contextual factors play a significant role in explaining the decision to use IPMS by companies (Hoque and James, 2000; Verbeeten and Rolleman, 2004; Chen, Duh and Lin, 2006). One long-established relationship is that such systems are more suitable and viable for larger companies (e.g. Hoque and James, 2000; Chenhall, R.H., 2003; Verbeeten and Boons, 2009; Chow et al., 1997). Theory suggests that size may affect the way organizations design and use performance management systems due to greater decentralization and structuring of activities. Consequently, in large companies a broader set of information and measurement issues arises (Kaplan and Atkinson, 1998). With our first hypothesis, we seek confirmation for this well-established stylized fact in our sample.

H1 (Contextual factors): Larger companies are more likely to use integrated performance measurement system.

Although a common feature of IPMS is that they have to be 'tailor-made' to individual company's needs and specific characteristics (particularly to its strategy), conceptually they are appropriate for various industries. In the literature, we mostly find case studies of firms from various industries. However, we can find quite a few cases of IPMS implementation in manufacturing industries (e.g. Hoque and James, 2000; Gosselin, 2005), while studies for services, public utilities and services, regulated industries, and for non-profit organizations are rare. Most empirical studies of IPMS usage, focusing on manufacturing industries, detect particular industry characteristics that significantly impact the implementation of IPMS such as the share of new products (Hoque and James, 2000), industry structure and uncertainty of the industrial environment (Verbeeten and Boon, 2009), while others report on the differences between manufacturing and service industries (Speckbacer, Bischof and Pfeiffer, 2003). Based on literature we cannot a priori expect any significant differences in the likelihood of IPMS usage among different industries. However, it could be argued that IPMS are more likely used in manufacturing and service industries than in other parts of the economy, like primary industries (agriculture, mining) and public service companies. Indeed, IPMS can be fitted to companies in various industries - conceptually even more to companies in industries where non-economic motives are important-, but the business processes in some industries are less technologically complex and governed more by natural conditions (e.g. primary industries), regulative legislation (e.g. utilities, telecommunications) or non-economic motives (e.g. health, education, and culture industries, non-profit organizations). The link between non-financial performance measures, financial results and strategy is thus perhaps more transparent and straightforward in these other industries, but less controllable. IPMS therefore offer less improvement for management decision-making over traditional systems. Since our sample contains companies from a wide range of industries (including agriculture, manufacturing, services, utilities, etc.), it allows us to directly test the hypothesis that:

H2 (Contextual factors): IPMS are more likely used by companies from manufacturing and service industries than by companies from other industries.

Market position of the company is another contextual factor that was used in the literature to explain the use of IPMS (Hoque and James, 2000; Speckbacer, Bischof and Pfeiffer, 2003). Merchant (1984) suggested that for firms in a weak market position the demand for adaptability and creativity would be greater than the demand for internal communication, while for firms in a strong market position, the demand for internal communication would be greater. Accordingly, companies that operate in more competitive markets are more likely to use IPMS, because competitive pressures encourage them to seek improvements in all areas of their business process and IPMS are thus a better tool to monitor and manage performance than traditional accounting systems. Survey data do not allow us to measure the market position of companies directly. Instead, we proxy market position by several other company characteristics: i) the number of competitors (less than 5,5-10, more than 10), ii) their presence in foreign markets, and iii) regulated market. The relationship between the three proxies and IPMS usage is quite clear-cut, our hypothesis is thus: 
H3 (Contextual factors): IPMS are more likely used by companies that i) have more competitors, ii) are present in foreign markets, and iii) do not operate in regulated markets.

The understanding of "successful performance" and business objectives of companies importantly influence the decision to adopt IPMS (Gosselin, 2005; Verbeeten and Boon, 2009) since non-financial performance measures supposedly provide better information on strategic dimensions that are not accurately captured by accounting performance measures (Govindarajan and Gupta, 1985; Lev, 2001). Accordingly, companies that define "successful performance" by following their strategy are more likely to implement IPMS. The survey used in our research asked companies to select and rank their understanding of "successful performance" (main business objectives) among the following offered: i) achieving goals of the owners, ii) achieving goals of various stakeholders, iii) following the business strategy, iv) keeping or v) increasing their market share, and vi) keeping-up with or vii) beating their competitors. We investigate how these business objectives affect the decision to implement IPMS. We expect that companies whose main business objective is achieving the goals of various stakeholders are more likely to use IPMS, because these systems offer better information related to stakeholders' satisfaction. Since a distinguishing feature of many IPMS is the link between business strategy and performance measurement indicators, we also expect that companies whose main business objective is following the strategy are more likely to use IPMS. On the other hand, we expect that companies who care mostly for the goals of owners are less likely to use IPMS, because they focus more on financial results and IPMS are less appealing to them. Some companies set their business objectives in terms of preserving or increasing their market share and keeping-up with or outdoing their competitors. In these cases, we expect that companies are more likely to use IPMS, if their main business objective is increasing the market share or outdoing the competitors, which is confirmed also in Verbeeten and Boon (2009). Our hypothesis regarding the effect of business objectives on the decision to adopt IPMS is the following:

H4 (Business objectives): IPMS are more likely used by companies whose main business objective is following the strategy, achieving goals of stakeholders, increasing the market share, and beating the competitors; IPMS are less likely used by companies whose main business objective is achieving goals of the owner, keeping the market share and keeping-up with the competitors.

Finally, we turn to knowledge about contemporary management tools as another aspect that influences the decision to implement IPMS. We proxy the knowledge about these tools by using two variables constructed from our survey questions that allow us to measure i) how many contemporary management tools (among 11 offered $^{1}$ ) the company is familiar with and ii) how many of such tools (among 11 offered) the company uses. Assuming that greater familiarity and usage of such concepts indicate companies that companies are more open towards learning about innovative management techniques and have a better knowledge about them, we expect these companies also to have a better understanding of IPMS. Our next hypothesis is therefore:

H5 (Knowledge): Companies that are familiar with more of the contemporary management tools are more likely to use IPMS. Similarly, companies that use more of the contemporary management tools are more likely to use IPMS.

\section{METHODOLOGY}

\subsection{Research Setting and Data}

Our setting is represented by a sample of companies operating in the Slovenian economy. Slovenia is a small economy with a population of about 2 million. It gained its sovereignty in June 1991, breaking away from the former Yugoslav federation. From 2004 Slovenia has been a member of the European Union and a member of the European Monetary Union since 2007. In 2008 Slovenia's GDP per capita (PPP) was at 90 per cent of the EU-27 average and 78 per cent of the EUR-15 average (Eurostat: GDP per capita in PPS, 2010).

The data source for our analysis is the survey "Cost management and contemporary management tools in Slovenian companies" conducted during the summer of 2008. The empirical research is based on an extensive

\footnotetext{
${ }^{1}$ The management tools offered in the survey are ABC, ABB, ABM, target costing, life-cycle costing, BSC, benchmarking, business process reengineering, just-in-time, TQM and kaizen.
} 
questionnaire, fully structured and with pre-coded responses. The questionnaires were filled in by using personal interviews with top managers or middle managers. We believe that personal interviews provide more complete and precise information than mail, telephone or e-mail questionnaires, taking into account the length of questionnaires. At the same time, they provide the opportunity for feedback in clarifying any questions a respondent has about the instructions or questions. Other advantages of personal interviews are moderate to fast speed of data collection, excellent respondent co-operation, low number of unanswered questions, and lowest possibility for respondent misunderstanding (Zikmund, 2000). We conducted personal interviews with 160 specially trained interviewers. ${ }^{2}$ Each interviewer questioned 2-3 companies. Slovenia is a relatively small country, so we could cover all geographical areas at a relatively low cost, which is usually not the case when using personal interviews (Zikmund, 2000).

This study is based on the research sample of 323 companies. Our sampling technique corresponds to the judgmental or purposive sampling ${ }^{3}$ as the population elements were selected based on the judgment of interviewers. Nevertheless, the sample is relatively big and offers a good representation of the whole population, as regards the size of companies, their geographical position and industry (branch) they belong to. 43 per cent of analysed companies use some form of the IPMS. Among these, 29 per cent use BSC while others use some other IPMS. The main objective of our research is to explore how particular factors such as contextual factors, business goals and the familiarity and use of the management tools impact the firm's decision to implement some form of the IPMS.

The sample consists of 34 per cent micro, 19 per cent small, 18 per cent medium, and 29 per cent large companies. Companies are classified according to valid Slovenian legislation at the time of conducting the interviews ${ }^{4} .32$ per cent of the companies operate in manufacturing, 31 per cent in service industries, 14 per cent in public services (such as public administration, defence, health, social security, education, culture), 7 per cent in financial industry, 2 per cent in primary industries (such as agriculture and mining) and utilities (such as electricity, water, and gas), and 4 per cent in other (non-classified) industries (such as ex-territorial organizations and non-profit organizations). 55 per cent of companies in the sample conduct their business also in foreign markets, while 17 per cent of the companies operate in a regulated environment.

Among the companies in our sample, 22 per cent of companies estimate that they have less than 5 competitors, 20 that they have from 5 to 9 competitors and 45 per cent that they have more than 10 direct competitors. The share of companies that find their competition to be more severe, i.e. they estimate the number of their competitors to be larger, is larger in service and among micro sized companies. At the same time firms in our sample estimate their market share to be on average 30 per cent of the market with the median value of 23 per cent.

In the survey we asked companies to define their understanding of "successful performance" by ranking the proposed business goals according to their importance and relevance. We use this question as a proxy for company's most important business objective(s). The surveyed companies were able to assign the same rank to more than one of the proposed objectives. The goals of the owners are ranked as the most important company's business objectives in 41 per cent of the investigated companies, the goals of other stakeholders in 29 per cent of the companies, while following the strategy is most important in 27 per cent of the firms. 12 per cent of the companies want first of all to increase their market share, while 8 per cent report their most important business objective to be the preservation of the existing market share. Only 5 per cent of companies have keeping-up with or beating the competition as their most important business objectives.

Eighty seven per cent of the investigated companies are familiar with at least one of the 11 proposed contemporary management tools such as $\mathrm{ABC}, \mathrm{ABB}, \mathrm{ABM}$, target costing, life-cycle costing, BSC, benchmarking,

\footnotetext{
2 The research was part of their postgraduate course work.

${ }^{3}$ For more on judgement or purposive sampling consult for example Churchill, 1999; Malhotra, 1999 or Zikmund, 2000.

4 "Micro company" fulfils two of the following criteria: average number of employees does not exceed 10, annual revenues are less than $€ 2$ million, assets at the end of the financial year do not exceed $€ 2$ million. "Small company" fulfils two of the following criteria: average number of employees does not exceed 50, annual revenues are less than $€ 7.3$ million, and assets at the end of the financial year do not exceed $€ 3.65$ million. "Medium company" is a company fulfilling two of the following criteria: average number of employees does not exceed 250, annual revenues account for less than $€ 29.2$ million, average assets at the end of business year do not exceed $€ 14.6$ million. Other companies were classified as "large companies".
} 
business process reengineering, just-in-time, TQM and kaizen, while the modus is 6. Among large firms the percentage of the firms being familiar with at least one of the management concepts is much larger at 98 per cent and modus of 11 . On the other hand, at least one of the 11 proposed management tools is used in 67 per cent of all of the investigated companies with the most frequent value being 1 . This percentage is even larger among large firms where it amounts to 87 per cent.

\subsection{The Model}

Assuming that the decision to use IPMS is conditional on the contextual factors, knowledge of contemporary management tools and specific business objectives, as presented in the previous section of the paper, our conceptual model of the relationship is of the following form

$$
P(y=1 \mid \mathbf{x})=f(\text { contextual factors, business objectives, knowledge })
$$

where:

- $\quad$ the dependent variable is IPMS usage;

- $\quad$ contextual factors are size (measured as the value of assets), industry, and market position (measured as regulation $[$ Reg], number of competitors [Comp], and presence in foreign markets [Foreign]);

- $\quad$ knowledge is measured via familiarity with management tools [Fam] and usage of management tools [Usage], and

- $\quad$ business objectives are strategy implementation [Strategy], stakeholders' interests [Stakeholders], owners' goals [Owner], keeping market share [Keep MS], increasing market share [Increase MS], keeping-up with the competitors [Keep-up], or beating the competitors [Beat].

We use logistic regression to model this relationship, therefore the general formulation of the model is:

$$
P(y=1 \mid \mathbf{x})=\frac{e^{y}}{1+e^{y}}
$$

and we estimate the following specific latent variable econometric model:

$$
\begin{aligned}
y^{*} & =\beta_{1}+\beta_{2} \text { Size }+\beta_{3 i} \text { Industry }_{i}+\beta_{4} \text { Reg }+\beta_{5} \text { Comp }+\beta_{6} \text { Foreign }+ \\
& +\beta_{7} \text { Fam }+\beta_{8} \text { Usage }+\beta_{9} \text { Objective }+e
\end{aligned}
$$

In order to avoid multicollinearity due to high correlation between different business objectives, we estimate seven separate models (each incorporating just one of the business objectives) to test the effect of business objectives on IPMS usage. Following our research propositions, we expect to find positive coefficients for size $\left(\beta_{2}\right)$, manufacturing and service industry $\left(\beta_{3 \operatorname{man}}\right.$ and $\left.\beta_{3 \mathrm{serv}}\right)$, number of competitors $\left(\beta_{5}\right)$, presence in foreign markets $\left(\beta_{6}\right)$, familiarity $\left(\beta_{7}\right)$ and usage of management tools $\left(\beta_{8}\right)$. Among the business objectives, we expect to find a positive coefficient $\beta_{9}$ for strategy implementation, stakeholders' interests, increasing market share, and beating the competition. We expect other coefficients to be negative.

\section{RESULTS}

First, we estimate the latent variable model (3) for the full sample of companies. In the next step, we estimate the model on subsamples of small and large companies to study the effect of company size more in-depth.

The results of the full sample estimations are presented in Table 1. The basic specification in column (1) does not include any business objective as explanatory variable, while columns (2) to (8) each contain specifications with one of the business objectives. An overview of the Wald test statistics reveals that all estimated models are statistically significant specifications of the studied relationship. Our model, in its various specifications, is generally able to explain around 27 to 30 per cent of the variance in IPMS usage. Considering that we study general factors affecting the decision to implement IPMS, which is governed to a great extent by company specific factors that are hard to measure across a sample of companies, this explanation power of the model is acceptable. 
Table 1: Estimation results for the full sample

\begin{tabular}{|c|c|c|c|c|c|c|c|c|c|c|c|c|c|c|c|c|}
\hline \multirow{2}{*}{$\begin{array}{l}\text { Dependent variable } \\
\text { = IPMS usage }\end{array}$} & \multicolumn{12}{|c|}{ All Companies } & \multirow[b]{2}{*}{ (7) } & \multirow{2}{*}{\multicolumn{3}{|c|}{ (8) }} \\
\hline & (1) & & (2) & & (3) & & (4) & & (5) & & (6) & & & & & \\
\hline \multirow[t]{2}{*}{ Assets (EUR mill.) } & 0.001 & $*$ & 0.001 & $*$ & 0.001 & $* *$ & 0.001 & $*$ & 0.000 & $* *$ & 0.001 & & 0.001 & $*$ & 0.001 & $*$ \\
\hline & 0.001 & & 0.001 & & 0.001 & & 0.001 & & 0.001 & & 0.001 & & 0.001 & & 0.001 & \\
\hline \multirow{2}{*}{ Agriculture \& Mining } & -0.960 & & -1.925 & & -1.620 & & -1.942 & & -1.603 & & -1.077 & & -1.926 & & -1.929 & \\
\hline & $(-1.421)$ & & $(-1.625)$ & & $(-1.613)$ & & $(-1.668)$ & & $(-1.511)$ & & $(-1.778)$ & & $(-1.676)$ & & $(-1.639)$ & \\
\hline \multirow[t]{2}{*}{ Manufacturing } & -0.362 & & -0.360 & & -0.345 & & -0.357 & & -0.147 & & -0.131 & & -0.354 & & -0.368 & \\
\hline & $(-0.641)$ & & $(-0.649)$ & & $(-0.691)$ & & $(-0.649)$ & & $(-0.653)$ & & $(-0.635)$ & & $(-0.653)$ & & $(-0.653)$ & \\
\hline \multirow[t]{2}{*}{ Utilities } & 0.150 & & 0.182 & & 0.306 & & 0.152 & & 0.379 & & -1.038 & & 0.153 & & 0.176 & \\
\hline & $(-1.280)$ & & $(-1.280)$ & & $(-1.446)$ & & $(-1.279)$ & & $(-1.512)$ & & $(-1.428)$ & & $(-1.283)$ & & $(-1.281)$ & \\
\hline \multirow[t]{2}{*}{ Service } & -0.799 & & -0.802 & & -0.696 & & -0.782 & & -0.694 & & -0.620 & & -0.779 & & -0.798 & \\
\hline & $(-0.663)$ & & $(-0.681)$ & & $(-0.728)$ & & $(-0.671)$ & & $(-0.667)$ & & $(-0.642)$ & & $(-0.675)$ & & $(-0.680)$ & \\
\hline \multirow[t]{2}{*}{ Financial } & -0.848 & & -1.027 & & -1.009 & & -1.025 & & -0.949 & & -1.019 & & -1.022 & & -1.018 & \\
\hline & $(-0.848)$ & & $(-0.880)$ & & $(-0.901)$ & & $(-0.877)$ & & $(-0.883)$ & & $(-0.867)$ & & $(-0.883)$ & & $(-0.883)$ & \\
\hline \multirow[t]{2}{*}{ Public services } & -1.600 & $* *$ & -1.620 & $* *$ & -1.391 & & -1.594 & $* *$ & -1.483 & $*$ & -1.893 & $* *$ & -1.589 & $* *$ & -1.613 & $* *$ \\
\hline & $(-0.787)$ & & $(-0.803)$ & & $(-0.867)$ & & $(-0.794)$ & & $(-0.800)$ & & $(-0.873)$ & & $(-0.796)$ & & $(-0.793)$ & \\
\hline \multirow[t]{2}{*}{ Other } & -2.031 & $*$ & -2.035 & $*$ & -2.022 & & -2.014 & $*$ & -2.015 & $*$ & -1.925 & $*$ & -2.016 & $*$ & -2.008 & $*$ \\
\hline & $(-1.141)$ & & $(-1.185)$ & & $(-1.290)$ & & $(-1.175)$ & & $(-1.206)$ & & $(-1.095)$ & & $(-1.167)$ & & $(-1.170)$ & \\
\hline \multirow[t]{2}{*}{ Regulation } & 0.062 & & 0.050 & & 0.057 & & 0.056 & & 0.027 & & 0.072 & & 0.055 & & 0.029 & \\
\hline & $(-0.424)$ & & $(-0.440)$ & & $(-0.442)$ & & $(-0.438)$ & & $(-0.468)$ & & $(-0.473)$ & & $(-0.438)$ & & $(-0.453)$ & \\
\hline \multirow[t]{2}{*}{ Competition } & -0.105 & & -0.125 & & -0.139 & & -0.127 & & -0.149 & & -0.119 & & -0.127 & & -0.126 & \\
\hline & $(-0.173)$ & & $(-0.175)$ & & $(-0.178)$ & & $(-0.177)$ & & $(-0.175)$ & & $(-0.182)$ & & $(-0.176)$ & & $(-0.177)$ & \\
\hline \multirow[t]{2}{*}{ Foreign markets } & 0.634 & $*$ & 0.694 & $*$ & 0.635 & $*$ & 0.694 & $* *$ & 0.709 & $* *$ & 0.696 & $*$ & 0.695 & $*$ & 0.699 & $* *$ \\
\hline & $(-0.352)$ & & $(-0.354)$ & & $(-0.358)$ & & $(-0.351)$ & & $(-0.361)$ & & $(-0.368)$ & & $(-0.355)$ & & $(-0.356)$ & \\
\hline \multirow[t]{2}{*}{ Familiarity } & 0.039 & & 0.048 & & 0.020 & & 0.048 & & 0.039 & & 0.098 & & 0.048 & & 0.048 & \\
\hline & $(-0.063)$ & & $(-0.064)$ & & $(-0.067)$ & & $(-0.065)$ & & $(-0.065)$ & & $(-0.070)$ & & $(-0.064)$ & & $(-0.064)$ & \\
\hline \multirow[t]{2}{*}{ Usage } & 0.524 & $* * *$ & 0.525 & $* * *$ & 0.506 & $* * *$ & 0.522 & $* * *$ & 0.540 & $* * *$ & 0.487 & $* * *$ & 0.522 & $* * *$ & 0.522 & $* * *$ \\
\hline & $(-0.110)$ & & $(-0.111)$ & & $(-0.113)$ & & $(-0.110)$ & & $(-0.110)$ & & $(-0.111)$ & & $(-0.110)$ & & $(-0.110)$ & \\
\hline Owner & & & 0.020 & & & & & & & & & & & & & \\
\hline Strategy & & & & & 0.168 & $* *$ & & & & & & & & & & \\
\hline & & & & & $(-0.076)$ & & & & & & & & & & & \\
\hline Stakeholders & & & & & & & $\begin{array}{l}-0.004 \\
(-0.075)\end{array}$ & & & & & & & & & \\
\hline Keep MS & & & & & & & & & -0.183 & & & & & & & \\
\hline & & & & & & & & & $(-0.120)$ & & & & & & & \\
\hline Increase MS & & & & & & & & & & & -0.107 & & & & & \\
\hline & & & & & & & & & & & $(-0.101)$ & & & & & \\
\hline Keep-up & & & & & & & & & & & & & -0.010 & & & \\
\hline & & & & & & & & & & & & & $(-0.206)$ & & & \\
\hline Beat & & & & & & & & & & & & & & & 0.040 & \\
\hline & & & & & & & & & & & & & & & $(-0.159)$ & \\
\hline _cons & -1.155 & & -1.242 & & -1.473 & $*$ & -1.184 & & -1.123 & & -1.289 & & -1.194 & & -1.198 & \\
\hline & $(-0.793)$ & & $(-0.795)$ & & $(-0.845)$ & & $(-0.812)$ & & $(-0.796)$ & & $(-0.793)$ & & $(-0.802)$ & & $(-0.805)$ & \\
\hline Wald $\chi^{2}$ & 69.67 & & 70.30 & & 71.08 & & 70.60 & & 70.55 & & 62.06 & & 70.12 & & 69.68 & \\
\hline Prob. $>\chi^{2}$ & 0.000 & & 0.000 & & 0.000 & & 0.000 & & 0.000 & & 0.000 & & 0.000 & & 0.000 & \\
\hline Pseudo $\mathrm{R}^{2}$ & 0.271 & & 0.281 & & 0.295 & & 0.281 & & 0.29 & & 0.294 & & 0.281 & & 0.281 & \\
\hline No. of observations & 260 & & 258 & & 258 & & 258 & & 258 & & 230 & & 258 & & 258 & \\
\hline
\end{tabular}

NOTE: The table reports beta coefficients and heteroskedasticity-robust standard errors (in parentheses), significance levels are denoted by $*<0.1, * *<0.05$, and $* * *<0.01$. Marginal effects for selected model specifications are reported in Table 4 (Appendix).

The results show that companies are more likely to use IPMS if they are larger, operate in foreign markets, use more management tools, and their main business objective is following the strategy. Companies are less likely to use IPMS if they operate in public services and other industries. All these findings are consistent with our expectations although some of the hypothesized relationships were not confirmed. 
First of all, the results confirm the well-established company size effect on the decision to implement IPMS. Not so surprisingly, usage of contemporary management tools turns out to be a powerful predictor of IPMS implementation: an average company is around 12 percentage points more likely to use IPMS if it uses one additional management tool (see marginal effects in Table 4 in the Appendix). Among various business objectives, only following the strategy significantly affects the decision to implement IPMS, but the effect is small: companies with following the strategy as their main business objective have only a 3.8 percentage point higher likelihood of introducing IPMS than other companies. On the other hand, company's presence in foreign market seems to have the largest effect on deciding to implement IPMS: companies operating in foreign markets are around 15 percentage point more likely to implement IPMS. However, the best predictors of IPMS usage (or better not-usage) are two industry variables: companies that operate in public services have a 28 percent lower probability of using IPMS, while companies operating in other (non-classified) industries have even 30 percentage point lower probability of using IPMS.

Other industry characteristics and measures of market position do not affect significantly the likelihood of implementing IPMS. Most of the industry variables signs are negative, only utilities companies seem to be more inclined to use IPMS; contrary to our expectations, manufacturing and service companies do not use IPMS more likely than other companies. Beside foreign market presence, market position is measured by regulation and competition, neither of which has a significant effect. Moreover, both have signs that are not consistent with our expectations. While more extensive usage of management tools has a significant effect on the likelihood of adopting IPMS, mere familiarity with these tools does not have such significant effect, but the positive sign is consistent with our expectation. Among business objectives, achieving owner's goals and the goals of various stakeholders have the signs opposite to our expectations.

To get a better understanding of our results, we performed further estimations of the basic model. We estimated the model separately by size groups. The companies were divided into three groups: small ("micro" and "small" companies), medium, and large companies. Because of insufficient observations or collinearity problems in medium companies' group, only results for small and large companies are presented (Tables 2 and 3, respectively).

Table 2 shows estimation results for the small companies subsample. Compared to the full sample models, the fit is generally slightly better.

Small companies are more likely to use IPMS if they are larger, use more contemporary management tools, and they strive primarily to beat the competitors. They will be less inclined to use IPMS if they operate in more competitive markets, but also if they are part of manufacturing, financial, public services industries or other nonclassified industries. As in the basic model, industry variables have the largest (negative) effect on IPMS usage. For example, small manufacturing firms have a roughly 18-percentage point smaller likelihood of using IPMS than other small firms. The negative effects of manufacturing and financial industry are not consistent with our expectations, while others are. Also the considerable negative effect of competition (around 7 percentage point) is surprising and not consistent with what we expected. On the other hand, the expected positive effects of using more management tools and trying to beat the competition are quite small in comparison: 4.4 percentage points for the former and 4.3 percentage points for the latter.

Regulation has the predicted negative sign, although it is not significant in all but the last specification (column (8)), indicating that small companies operating in regulated markets are probably less likely to use IPMS. Surprisingly, also the effect of foreign market presence has a negative sign (not significant). As in the basic model, familiarity with contemporary management tools probably increases the likelihood of using IPMS, but not significantly. While beating the competitors is the only business objective that encourages small companies to use IPMS, almost all of them have positive signs. Among them, achieving owner's goals and keeping up with competition have the wrong sign. 
Table 2: Estimation results for the subsample of small companies

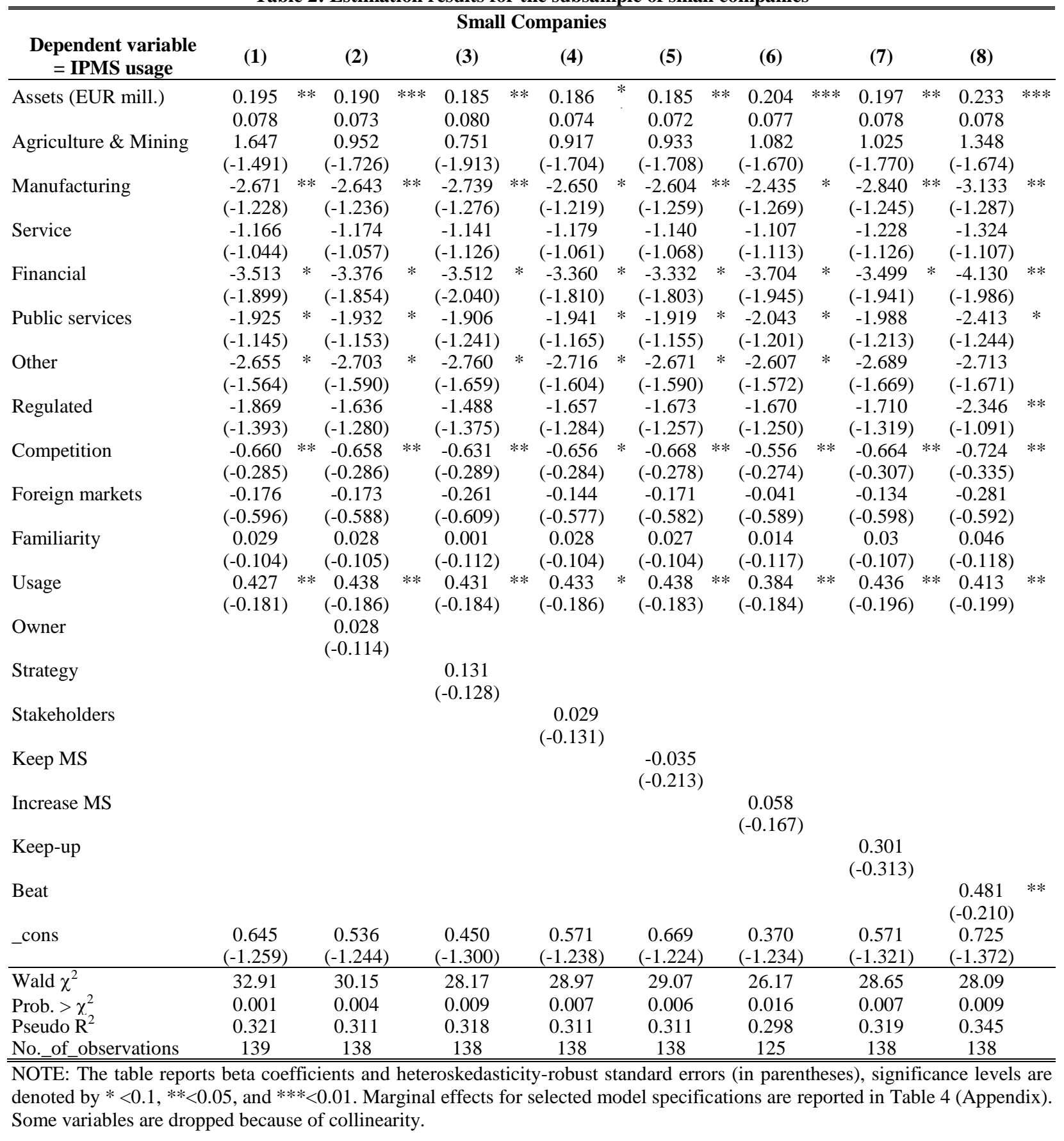

Table 3 presents the estimation results for the large companies subsample. Apart from the specification in column (6) - containing increasing market share as business objective- other specifications are all statistically significant and explaining around $30 \%$ of the variance in IPSM usage.

Large companies that are more likely to use IPMS operate in manufacturing industries, in regulated markets, and use more contemporary management tools. They are also less likely to use IPMS if their primary business objective is to keep their market share (although only at 10.3 percent significance level). Manufacturing 
firms have a 35-percentage point higher likelihood of using IPMS than firms form other industries. As expected, also companies from financial and service industry are more likely to use IPMS, although this effect is not significant. The effect of regulation is surprisingly large (around 15 percentage points) and not consistent with our expectations. Usage of contemporary management tools has the largest effect on IPMS implementation in large companies: an average company has a 9.5 percentage points higher probability of using IPMS if it uses one additional such tool. Familiarity with these tools has a positive, but smaller effect. This effect is significant only in one of the model specifications (column (6)).

Table 3: Estimations results for the subsample of large companies

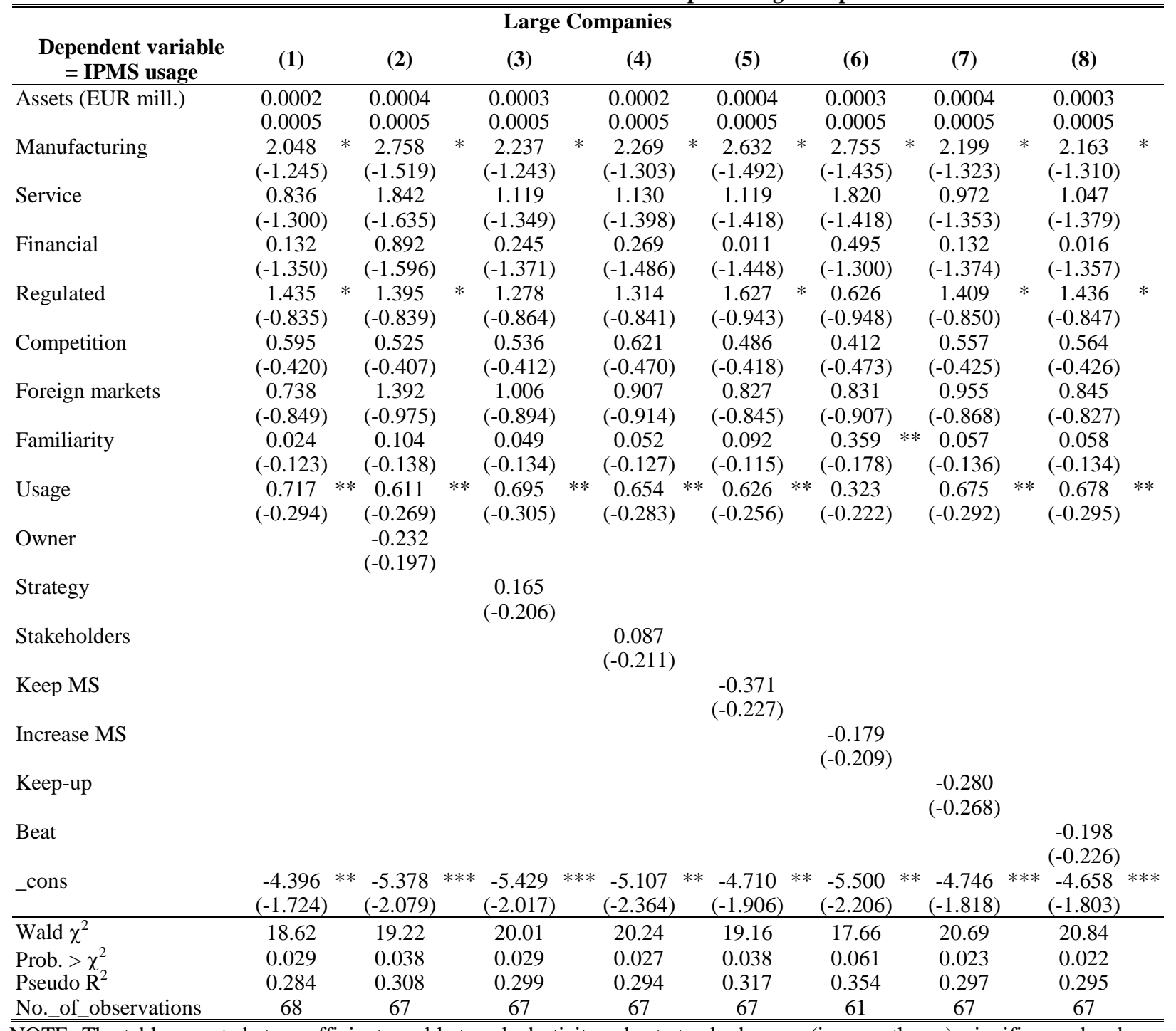

NOTE: The table reports beta coefficients and heteroskedasticity-robust standard errors (in parentheses), significance levels are denoted by $*<0.1, * *<0.05$, and $* * *<0.01$. Marginal effects for selected model specifications are reported in Table 4 (Appendix). Some variables are dropped because of collinearity.

Almost all of the statistically insignificant variables have the predicted sign. Companies are thus possibly more likely to use IPMS if they are larger, operate in more competitive and foreign markets, and have as primary business objectives following the strategy and achieving the goals of various stakeholders. Companies that care more for the owner's goals or try just to keep-up with the competitors are probably less likely to use IPMS. Contrary 
to our expectations, trying to increase the market share and beating the competition do not seem to encourage large companies to use IPMS.

\section{DISCUSSION}

The purpose of this study was to investigate the relationship between the use of IPMS and contextual factors, knowledge about contemporary management tools, and business objectives. We tested our research propositions regarding the influence of all these factors by using survey data and a logistic regression model. Overall, our results confirm contextual factors, such as company size and industry, and knowledge about management tools as most important determinants of IPMS usage. Although market position and business objectives also receive some support for their influence, the results are generally weaker and more ambiguous.

The study confirms the well-known fact that companies are more likely to use IPMS if they are larger. In addition to that, our estimations exposed a threshold related to the size effect: once a company is large enough, increasing its size does not affect greater usage of IPMS anymore.

One other confirmation of the study is that companies are more likely to use IPMS, if their main business objective is following the strategy. This implies that companies understand the purpose of IPMS is relating key performance indicators to the strategy and they use IPMS as a tool helping them implement the strategy. However, the effect of following the strategy as primary business objective on greater IPMS usage is small and generally speaking particular business objectives do not have an important effect on the decision to implement IPMS. Among business objectives, beating the competition seems to encourage small companies to use IPMS and keeping the market share seems to discourage large companies from the use of IPMS. Both findings are in line with what we have expected. Although the effect of achieving owner's goals was never significant, the results imply that focusing on owner's goals increases the use of IMPS in small companies and decreases its use in large companies. This can be explained by the fact that most small company owners are also managers in these companies and thus find IPMS useful for better performance management. In large companies, however, owners' and managers' interests are not aligned to the same extent and owners typically care more for financial results.

The results have also confirmed that knowledge about contemporary management tools (mostly obtained via using such approaches) indeed increases the likelihood that a company will decide to implement IPMS. While the effect is of minor importance for small companies, it is considerably greater for large companies.

However, there are other important differences between the factors determining IPMS usage in small and large companies. A typical small firm that uses IPMS is ambitious in its business objectives, quite large for this size group, has knowledge about contemporary management tools, operates in less competitive and domestic markets, which are not regulated, and is less likely to operate in manufacturing industry. Contrary to our expectations, small companies that operate in more competitive and foreign markets do not use IPMS more likely than others. The reason for this might be related to greater competitive pressure forcing small companies to dedicate their resources (time, money, people) fully to the challenges of competition and not to implementing innovative management performance techniques. We can partly support this explanation by looking at some of the reasons for not implementing BSC in small companies: 50 per cent of non-users are not familiar with the concept and 18 per cent blame high implementation costs.

On the other hand, a large firm that most likely uses IPMS tends to be a manufacturing firm, operating in a regulated market, and with extensive knowledge about contemporary management tools. Contrary to our expectations, companies in regulated markets tend to use IPMS more than others. One explanation for this finding could be that regulative authorities require reporting about non-financial aspects of performance and hence, stimulate regulated companies to use IPMS. Another explanation could be related to companies from regulated industries having more available resources (time, money, people) to invest in IPMS implementation due to less intensive competitive pressures.

Surprisingly, our results show that overall manufacturing and service companies are not more likely to use IPMS, instead utilities companies seem to be more inclined to use them. Since most of the utilities companies 
operate in regulated markets, the explanation for this finding is probably related to regulation as above. The effect of manufacturing is strongly negative for small companies, but strongly positive for large companies.

Another interesting finding of the study is that companies operating in public services and other (nonclassified) industries are much less likely to use IPMS than other companies. Although this is consistent with our expectations, we would like to advocate for greater use of IPMS by these companies. Considering that such companies typically have to follow motives that are not only economic or financial, IPMS are conceptually even more appropriate for them than other companies. The problem faced by these companies is mostly related to lack of knowledge about contemporary management tools and in particular about BSC: 17.4 per cent of them are not familiar with any of the management tools mentioned in the questionnaire, 49 per cent do not use any of these tools, and 52 per cent are not familiar with BSC, which are the highest shares among all industry groups.

The literature review revealed a deficiency of empirical studies of IPMS usage determinants based on large samples covering different industries and all company size groups. Our study fills this gap by analyzing a large sample of Slovenian companies and provides relevant empirical findings regarding factors impacting companies' decision to implement IPMS. Moreover, the study exposed some interesting relationships that require further research.

\section{AUTHOR INFORMATION}

Mojea Marc is a teaching and research assistant at the Department of Management and Organization at Faculty of Economics, University of Ljubljana (Slovenia). She holds a Master degree in Finance from University of Ljubljana and a PhD degree in Economics from University of Siena (Italy). Her research interests range from banking and financing of companies, performance measurement in companies to innovation activity and intellectual property of companies. Her work has been published in international academic journals. She has working experience from NLB bank (Slovenia) and has been working on many corporate consulting projects for Slovenian companies since 2001.

Darja Peljhan is an assistant professor at the Department of Management and Organization at the Faculty of Economics, University of Ljubljana. Her research interests are in management control systems and performance management. She attended many international conferences, where she presented papers in her research area and published several articles in European and US journals. She is a reviewer in several journals from her research field.

Nina Ponikvar, $\mathrm{PhD}$ is an assistant professor of economics at University of Ljubljana, Faculty of Economics. She teaches microeconomics, managerial economics and business analysis courses. She holds a Ph.D. in economics from the University of Ljubljana (2008) with the title of her dissertation Markup determinants in manufacturing industries: The case of Slovenia. She has published papers in international journals such as Journal of business economics and management, Prague economic papers, and Economic and business review for central and southeastern Europe. Her current research fields are microeconomics, industrial economics and business performance analysis.

Aleksandra Sobota is a teaching assistant at the Department of Management and Organization at Faculty of Economics, University of Ljubljana (Slovenia). Her research fields are cost management and performance management. She attended several international conferences, where she presented papers in her research area. Currently she is working on her master's thesis.

Metka Tekavcic is a professor at the Department of Management and Organization at the Faculty of Economics, University of Ljubljana. She is the Head of the Institute of Management and Organisation. Her research interests are in cost management and performance measurement. She attended many international conferences, where she presented papers in her research area and published several articles in European and US journals. She is a member of editorial boards in several journals from her research field. 


\section{REFERENCES}

1. Chen, H., Duh, R.-R. \& Lin, J.C.-C. (2006), The Determinants of Implementation Stages of Balanced Scorecard. International Journal of Management and Decision Making, 7, 4, p. 1.

2. Chenhall, R.H. (2003), Management Control Systems Design within Its Organizational Context: Findings from Contingency-based Research and Directions for the Future. Accounting, Organizations and Society, $28,127-168$.

3. Chow, C., K. Haddad \& J. Williamson (1997) Applying the Balanced Scorecard to Small Companies. Management Accounting, 59(2), 21-27.

4. Gosselin, M. (2005), An Empirical Study of Performance Measurement in Manufacturing Firms, International Journal of Productivity and Performance Management, 54, 4/5, p. 419-437.

5. Govindarajan, V. \& Gupta, A.K. (1985), Linking Control Systems to Business Unit Strategy: Impact on Performance. Accounting, Organizations and Society, 10, 1, p. 51-66.

6. Hoque, Z. \& James, W. (2000), Linking Balanced Scorecard Measures to Size and Market Factors: Impact on Organizational Performance, Journal of Management Accounting Research, 12, 1-17.

7. Kaplan, R. S. and Norton, D. P. (1992) Balanced Scorecard - Measures That Drive Performance. Harvard Business Review, 70(1), 71-79.

8. Kaplan, R.S. and Atkinson, A.A. (1998), Advanced Management Accounting, Englewood Cliffs, NJ: Prentice Hall.

9. Lev, B. (2001), Intangibles: Management, Measurement and Reporting. Washington, Brookings Institution Press.

10. Merchant, K.A. (1984), Influences on Departmental budgeting: An Empirical Examination of a Contingency model. Accounting, Organizations and Society, 9, 3/4, p. 291-307.

11. Spechbacher, G., Bischof, J. \& Pfeiffer, T. (2003), A Descriptive Analysis on the Implementation of Balanced Scorecard in German-speaking Countries, Management Accounting Research, 14, 361-387.

12. Verbeeten, F.H.M. \& Rolleman H. (2004), Contextual Determinants of the Use of Corporate Performance Measurement Systems: An Agency Perspective.

13. Verbeeten, F.H.M. and Boons, A.N.A.M. (2009), Strategic Priorities, Performance Measures and Performance: An Empirical Analysis of Dutch Firms. European Management Journal, 27, p. 113-128. 


\section{APPENDIX}

Table 4: Marginal effects for selected models

\begin{tabular}{|c|c|c|c|c|c|c|}
\hline \multirow[b]{2}{*}{$\begin{array}{l}\text { Dependent variable } \\
\text { = IPMS usage }\end{array}$} & \multicolumn{6}{|c|}{ Marginal Effects - Selected Models } \\
\hline & All (1) & All (3) & Small (1) & Small (8) & Large (1) & Large (6) \\
\hline Assets (EUR mill.) & 0.0002 & 0.0002 & $0.0202 * *$ & $0.0211 * * *$ & 0.000031 & 0.000032 \\
\hline Agriculture \& Mining (d) & -0.184 & -0.254 & 0.286 & 0.198 & & \\
\hline Manufacturing (d) & -0.082 & -0.076 & $-0.186 * *$ & $-0.184 * *$ & $0.291 *$ & $0.365^{*}$ \\
\hline Public utilities (d) & 0.035 & 0.072 & & & & \\
\hline Service $(d)$ & -0.174 & -0.149 & -0.105 & -0.103 & 0.098 & 0.168 \\
\hline Financial (d) & -0.169 & -0.189 & $-0.126^{*}$ & $-0.113 * *$ & 0.017 & 0.054 \\
\hline Public services (d) & -0.287 & -0.251 & $-0.142 *$ & $-0.146^{* *}$ & & \\
\hline Other $(d)$ & -0.306 & -0.294 & $-0.131 *$ & -0.115 & & \\
\hline Regulated (d) & 0.014 & 0.013 & -0.114 & $-0.111 * *$ & $0.155^{*}$ & 0.069 \\
\hline Competition & -0.024 & -0.031 & $-0.068 *$ & $-0.065 * *$ & 0.081 & 0.051 \\
\hline Foreign markets (d) & 0.144 & 0.141 & -0.018 & -0.025 & 0.119 & 0.127 \\
\hline Familiarity & 0.009 & 0.004 & 0.003 & 0.004 & 0.003 & $0.044 *$ \\
\hline Usage & 0.120 & 0.114 & $0.044 *$ & $0.037 * *$ & $0.098 * *$ & 0.040 \\
\hline \multicolumn{7}{|l|}{ Owner } \\
\hline Strategy & & 0.038 & & & & \\
\hline \multicolumn{7}{|l|}{ Stakeholders } \\
\hline \multicolumn{7}{|l|}{ Keep MS } \\
\hline Increase MS & & & & & & -0.022 \\
\hline \multicolumn{7}{|l|}{ Keep-up } \\
\hline Beat & & & & $0.043 * *$ & & \\
\hline Prob. & 0.000 & 0.000 & 0.001 & 0.009 & 0.029 & 0.061 \\
\hline Pseudo_R-squared & 0.271 & 0.295 & 0.321 & 0.345 & 0.284 & 0.354 \\
\hline No._of_observations & 260 & 258 & 139 & 138 & 68 & 61 \\
\hline
\end{tabular}

NOTE: (d) denotes dummy variables where marginal effects are calculated for a discrete change of the dummy variable from 0 to 1. 
NOTES 